\title{
Pengolahan Alang-Alang (Imperata Cylindrica) Sebagai Bahan Baku Furfural Melalui Pretreatment Pemanasan Resistive
}

\author{
Processing Alang-Alang (Imperata Cylindrica) As Raw Material of Furfural through Pretreatment of Resistive \\ Heating
}

\author{
Yusuf Hendrawan ${ }^{1 *}$, Yosua ${ }^{1}$, Siti Mariyah Ulfa ${ }^{2}$ \\ 1Jurusan Keteknikan Pertanian - Fakultas Teknologi Pertnian - Universitas Brawijaya \\ ${ }^{2}$ Jurusan Kimia - Fakultas Teknologi Pertanian - Universitas Brawijaya \\ Jl. Veteran, Malang 65145
}

*Penulis Korespodensi, E-mail: yusufhendrawan@gmail.com

\begin{abstract}
ABSTRAK
Pada kajian ini, penulis bermaksud untuk mengetahui pengaruh proses pretreatment resistive heating pada proses pembuatan furfural dari bahan alang-alang dan juga untuk mengetahui karakter furfural yang dihasilkan. Rancangan percobaan terdiri dari 2 faktor, faktor 1 yaitu konsentrasi $\mathrm{NaOH}(0,01 ; 0,05$; $0,09 \mathrm{M})$ dan faktor 2 yaitu suhu pretreatment $\left(65,75,85^{\circ} \mathrm{C}\right)$. Hasil penelitian menunjukan bahwa pretreatment pemanasan resistive dapat menghasilkan rendemen furfural yang lebih banyak dibanding dengan rendemen tanpa pretreatment dan juga konsentrasi $\mathrm{NaOH}$ dan suhu pretreatment berpengaruh terhadap jumlah rendemen furfural hasil hidrolisis. Perlakuan terbaik diperoleh pada kombinasi perlakuan suhu pemanasan $65^{\circ} \mathrm{C}$ dengan konsentrasi $\mathrm{NaOH} \quad 0,01 \mathrm{M}$, yaitu didapatkan rata-rata rendemen furfural sebanyak 7,34\%. Karakterisasi melalui pengukuran massa jenis, kromotografi lapis tipis (KLT), spektrofotometri UV-Vis, spektrofotometri FTIR, dan gas chromatography (GC) menunjukan bahwa karakter furfural yang didapat memiliki kemiripan dengan furfural standar.
\end{abstract}

Kata kunci: Alang-alang, Furfural, Pretreatment, Resistive, Lignoselulosa

\section{ABSTRACT}

On this study, the authors intend to investigate the effect of pretreatment processes resistive heating in the production of furfural from reeds and also to know the character of furfural produced. The experimental design consisted of two factors, the first factor is concentration of $\mathrm{NaOH}(0.01 ; 0.05 ; 0.09 \mathrm{M})$ and the second factor is the temperature pretreatment $\left(65,75,85^{\circ} \mathrm{C}\right)$. The results showed that pretreatment resistive heating can produce furfural yield more than the yield without pretreatment and also the concentration of $\mathrm{NaOH}$ pretreatment and temperature affect the amount of furfural hydrolysis yield. The best treatment was obtained at the heating temperature of $65^{\circ} \mathrm{C}$ combined treatment with $\mathrm{NaOH}$ concentration of $0.01 \mathrm{M}$, which obtained an average yield of furfural as much as 7.34\%. Characterization by measuring the density, thin-layer chromatography (TLC), UV-Vis spectrophotometry, FTIR spectrophotometry, and gas chromatography (GC) showed that furfural obtained character has similarities with standard furfural.

Keywords: Reeds, Furfural, Pretreatment, Resistive, Lignocellulose

Diterima: 10 Desember 2018; Disetujui: 31 Desember 2018 DOI : 10.24198/jt.vol12n2.1

\section{PENDAHULUAN}

Indonesia merupakan negara yang sedang berkembang, termasuk di bidang industri. Kondisi ini mendorong munculnya berbagai macam industri, namun karena bahan baku tidak tersedia di Indonesia sehingga banyak diantaranya diperoleh dengan cara impor dari luar negeri. Furfural memiliki aplikasi yang cukup luas dalam beberapa industri. Hingga saat ini seluruh kebutuhan furfural dalam negeri diperoleh melalui impor. Impor terbesar diperoleh dari Cina yang saat ini menguasai $72 \%$ pasar furfural dunia (Wijanarko, dkk, 2006). Furfural sendiri dapat diperoleh dari bahanbahan pertanian yang mengandung senyawa pentosan seperti alang-alang. Alang-alang (Imperata cylindrica (L.) Beauv) merupakan tumbuhan rumput menahun yang tersebar hampir di seluruh belahan bumi dan dianggap sebagai gulma pada lahan pertanian. Dilihat dari kandungan kimianya, gulma tersebut mengandung $\alpha$-selulosa 40,22\%, holoselulosa 
$59,62 \%$, hemiselulosa (pentosan) 18,40\%, dan lignin 31,29\% (Kartikasari dkk., 2013).

Proses pretreatment dilakukan untuk mengkondisikan bahan-bahan lignoselulosa baik dari segi struktur dan ukuran dengan memecah dan menghilangkan kandungan lignin dan hemiselulosa, merusak struktur kristal dari selulosa serta meningkatkan porositas bahan (Sun dan Cheng, 2002). Salah satu inovasi pretreatment pada bahan lignoselulosa adalah dengan pemberian pemanasan resistive. Sejauh ini metode resistive heating hanya sebatas pada produk hasil pertanian (makanan) dan belum diketahui pengaruhnya terhadap pretreatment pada bahan lignoselulosa pada proses pembuatan furfural. Maka dari itu perlu dilakukannya penelitian berkaitan dengan proses pretreatment melalui metode resistive heating pada proses pembuatan furfural.

\section{BAHAN DAN METODE}

\section{Bahan}

Bahan utama yang digunakan adalah alangalang (Imperata cylindrica (L.) Beauv) yang diperoleh dari sekitar tanah kosong komplek Sigura-gura, Kota Malang. Alang-alang yang dipilih adalah alang-alang yang telah dewasa namun belum berbunga dengan ukuran panjang daun lebih dari $40 \mathrm{~cm}$ dan berwarna hijau tua. Kemudian alang-alang yang telah didapat dikeringkan selama 1 minggu. Setelah kering, kemudian dilakukan proses pengecilan ukuran dengan diparut dan diayak dengan ukuran 6 mesh. Selain itu, bahan kimia yang digunakan adalah $\mathrm{H}_{2} \mathrm{SO}_{4} 10 \%$ (Smart Lab), $\mathrm{NaCl}$, kloroform MERCK, furfural standar MERCK, akuades, dan $\mathrm{NaOH}$ teknis $(0,01 \mathrm{M} ; 0,05 \mathrm{M} ; 0,09 \mathrm{M})$.

\section{Alat}

Alat-alat yang digunakan dalam penelitian ini adalah reaktor resistive heating, plat KLT, thermocouple tipe $\mathrm{K}$, thermocontrol display OMRON, pH meter, seperangkat alat destilasi, spektrofotometer UV-Vis Shimadzu 1601, spektrofotometer FTIR Shimadzu 8400S, dan Gas Chromatography (GC) HP 5890.

\section{Metode}

Penelitian ini dibagi menjadi dua bagian, pertama adalah pengolahan alang-alang tanpa melalui tahap pretreatment pemanasan resistive dan dengan melalui tahap pretreatment pemanasan resistive. Pada pengolahan tanpa melalui tahap pretreatment diterapkan variasi bagian alang-alang yang diproses, yaitu bagian daun dan batang. Kemudian pada pengolahan dengan melalui tahap pretreatment dilakukan variasi pada proses pretreatment, berupa variasi suhu yang diberikan selama pemanasan dan konsentrasi $\mathrm{NaOH}$. Furfural dari perlakuan terbaik yang diperoleh dari tahap hidrolisis kemudian diuji (karakterisasi) sifat fisik dan sifat kimianya secara kuantitatif dengan pengukuran massa jenis dan secara kualitatif dengan metode kromotografi lapis tipis (KLT), spektrofotometeri UV-Vis, spektrofotometri FTIR, dan gas chromatography (GC). Analisa hasil dilakukan dengan melakukan interpretasi dan elusidasi hasil karakterisasi produk furfural. Secara rinci rancangan penelitian dengan perlakuan pretreatment disusun pada Tabel berikut:

Tabel 1. Rancangan perlakuan pretreatment

\begin{tabular}{cccc}
\hline Konsentrasi & \multicolumn{3}{c}{ Suhu $\left({ }^{\circ} \mathbf{C}\right)$} \\
\cline { 2 - 4 } NaOH (M) & $\mathbf{6 5}$ & $\mathbf{7 5}$ & $\mathbf{8 5}$ \\
\hline 0,01 & $0,01-65$ & $0,01-75$ & $0,01-85$ \\
0,05 & $0,05-65$ & $0,05-75$ & $0,05-85$ \\
0,09 & $0,09-65$ & $0,09-75$ & $0,09-85$ \\
\hline
\end{tabular}

\section{HASIL DAN PEMBAHASAN}

Proses hidrolisis furfural tanpa pretreatment dilakukan menggunakan 2 bagian dari alangalang, yaitu bagian daun dan bagian batang. Hidrolisis furfural bagian daun dilakukan sebanyak 3 kali, begitu juga pada bagian batang. Rendemen furfural hasil hidrolisis disajikan pada tabel berikut:

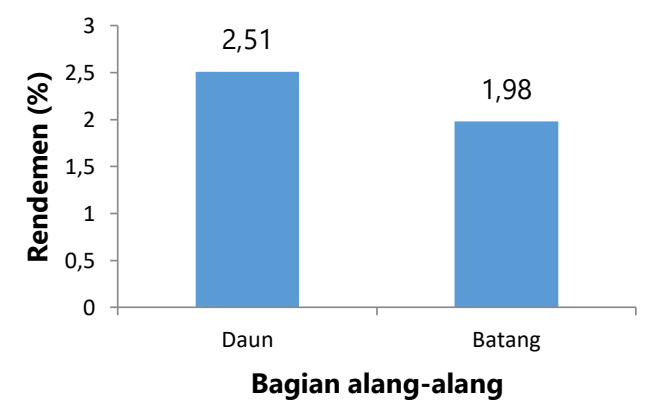

Gambar 1. Grafik rerata rendemen furfural hasil hidrolisis tanpa pretreatment

Berdasarkan Gambar 1, diketahui kondisi optimum perolehan rerata rendemen furfural tanpa pretreatment yang paling banyak terdapat pada bagian daun dari alang-alang, yakni 2,51\%. Jumlah furfural yang didapat sangat bergantung pada kondisi tahap hidrolisis, terutama yaitu jumlah katalis yang digunakan, lamanya proses berlangsung, dan kondisi bahan itu sendiri. Hidrolisis dilakukan dengan penambahan $\mathrm{H}_{2} \mathrm{SO}_{4}$ $10 \%$ sebanyak $250 \mathrm{~mL}$ dan waktu hidrolisis selama 5 jam. Sebelum dihidrolisis, alang-alang tersebut terlebih dahulu dilakukan proses 
penjemuran dengan cara diangin-anginkan selama 2 minggu. Waktu penjemuran berhubungan dengan kandungan metabolit sekunder dalam suatu sampel tanaman atau bahan alam. Sedangkan jumlah katalis berpengaruh terhadap konversi gula polimer (pentosan) menjadi gula monomer (pentosa) (Gauru, 2002). Hasil penelitian ini didukung oleh laporan Setyadji (2007) yang menyatakan bahwa semakin besar jumlah $\mathrm{H}_{2} \mathrm{SO}_{4}$ maka penguraian pentosan dalam alang-alang semakin sempurna sehingga hasil furfural semakin besar. Selain itu penambahan waktu reaksi hingga 5-8 jam menyebabkan kontak antara zat-zat yang bereaksi (sanyawa pentosan dengan asam sulfat) lebih lama sehingga waktu untuk menguraikan gula polimer (pentosan) menjadi gula monomer (pentosa) terjadi secara optimum (Setyadji, 2007).

Kemudian analisis dengan KLT juga dilakukan untuk mengetahui nilai faktor retensi (Rf) senyawa hasil isolasi dan sifat kepolarannya, dibandingankan dengan senyawa furfural standar. Nilai Rf furfural standar dan hasil isolasi ditunjukkan pada Tabel 2.

Tabel 2. Nilai Rf furfural hasil hidrolisis tanpa pretreatmet*

\begin{tabular}{|c|c|c|c|}
\hline Sampel & \multicolumn{2}{|c|}{$\begin{array}{l}\text { Nilai Rf Furfural } \\
\text { Hidrolisis }\end{array}$} & $\begin{array}{l}\text { Nilai Rf Furfural } \\
\text { Standar }\end{array}$ \\
\hline \multirow{3}{*}{ 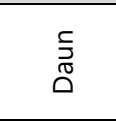 } & 1 & 0,363 & \multirow{3}{*}{0,377} \\
\hline & 2 & 0,469 & \\
\hline & 3 & 0,338 & \\
\hline \multirow{3}{*}{ 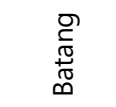 } & 1 & 0,331 & \multirow{3}{*}{0,338} \\
\hline & 2 & 0,338 & \\
\hline & 3 & 0,338 & \\
\hline
\end{tabular}

$\left.{ }^{\star}\right)$ eluent Etil asetat: Heksana $=1: 9$

Apabila nilai Rf kedua senyawa sama, dapat diindikasikan senyawa yang dihasilkan adalah furfural dengan derajat kemurnian yang tinggi. Nilai Rf furfural dari daun maupun batang adalah 0,32-0,47; sedangkan furfural standart juga menunjukkan Rf yang kurang lebih sama. Hal ini mengindikasikan senyawa yang dihasilkan dari hidrolisis alang-alang adalah furfural. Dari hasil di atas, maka dapat dikatakan bahwa baik batang maupun daun sama-sama berpotensi untuk digunakan sebagai bahan baku pembuatan furfural.

Hasil isolasi furfural melalui pretreatment resistive heating menunjukan jumlah rendemen yang lebih banyak di hampir semua perlakuan bila dibandingkan dengan isolasi furfural tanpa melalui pretreatment, yang mana rerata rendemen terbanyak yang didapat hanya 2,51\%. Kemudian jumlah rendemen furfural terbayak terdapat pada perlakuan pretreatment dengan suhu $65^{\circ} \mathrm{C}$ dan konsentrasi larutan $\mathrm{NaOH}$ sebesar $0,01 \mathrm{M}$, yakni sebanyak 7,34\%.

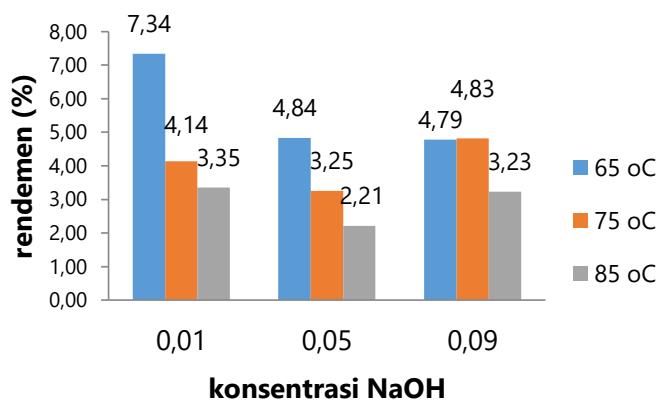

Gambar 2. Grafik rerata rendemen furfural hasil hidrolisis dengan pretreatment

Secara umum hasil menunjukan bahwa pengaruh peningkatan suhu pretreatment pemanasan resistive akan menghasilkan rendemen furfural yang semakin sedikit. Kemudian juga konsentrasi pelarut $\mathrm{NaOH}$ tinggi berpotensi untuk menurunkan rendemen furfural yang didapat. $\mathrm{Hal}$ ini dikarenakan $\mathrm{NaOH}$ yang digunakan berupa padatan memiliki tingkat kelarutan yang tinggi apabila berada pada temperatur tinggi (Elwin dkk., 2014). Hal ini disebabkan karena $\mathrm{NaOH}$ yang bersifat sebagai basa kuat memecah struktur hemiselulosa bahan dan kemudian melarutkannya. Sementara sumber utama pembentuk furfural adalah pentosan yang merupakan bentukan gula sederhana dari hemiselulosa. Namun di samping itu, pada perlakuan kadar larutan $\mathrm{NaOH} \mathrm{0,09} \mathrm{M}$ memperlihatkan kecendrungan peningkatan rendemen furfural bila dibandingkan dengan kadar larutan $\mathrm{NaOH} 0,05 \mathrm{M}$. Hal ini bisa jadi disebabkan karena penambahan $\mathrm{NaOH}$ pada proses pretreatment dapat menurunkan kandungan lignin yang cukup besar, karena reaksi pemutusan ikatan lignin menjadi lebih cepat (Dehani, 2013). Berdasarkan Jalaluddin dan Rizal (2005) dalam Normalasari dkk. (2015), peningkatan konsentrasi $\mathrm{NaOH}$ berarti meningkatkan jumlah ion [OH-] di dalam cairan. Ion-ion [OH-] ini akan memutuskan ikatanikatan dari struktur dasar pembentuk lignin, sehingga lignin menjadi lebih mudah untuk dilarutkan.

Kemudian analisis dengan KLT juga dilakukan untuk nilai faktor retensi (Rf) senyawa hasil isolasi, dibandingankan dengan senyawa furfural standar. Nilai $\mathrm{Rf}$ furfural standar dan hasil isolasi ditunjukkan pada Tabel 3. 
Tabel 3. Nilai Rf furfural hasil hidrolisis dengan pretreatmet*

\begin{tabular}{|c|c|c|c|}
\hline & \multirow[b]{2}{*}{ Sampel } & \multicolumn{2}{|c|}{ Nilai Rf } \\
\hline & & $\begin{array}{l}\text { Furfural } \\
\text { Hidrolisis }\end{array}$ & $\begin{array}{l}\text { Furfural } \\
\text { Standar }\end{array}$ \\
\hline \multirow{9}{*}{ 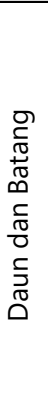 } & $0.09 \mathrm{M}-65^{\circ} \mathrm{C}$ & 0,250 & \\
\hline & $0.09 \mathrm{M}-75^{\circ} \mathrm{C}$ & 0,275 & 0,275 \\
\hline & $0.09 \mathrm{M}-85^{\circ} \mathrm{C}$ & 0,275 & \\
\hline & $0.05 \mathrm{M}-65^{\circ} \mathrm{C}$ & 0,238 & \\
\hline & $0.05 \mathrm{M}-75^{\circ} \mathrm{C}$ & 0,263 & 0,250 \\
\hline & $0.05 \mathrm{M}-85^{\circ} \mathrm{C}$ & 0,250 & \\
\hline & $0.01 \mathrm{M}-65^{\circ} \mathrm{C}$ & 0,313 & \\
\hline & $0.01 \mathrm{M}-75^{\circ} \mathrm{C}$ & 0,313 & 0,300 \\
\hline & $0.01 \mathrm{M}-85^{\circ} \mathrm{C}$ & 0,275 & \\
\hline
\end{tabular}

*) eluent Etil asetat:Heksana $=1: 9$

Nilai Rf yang didapat berdasarkan dari analisa KLT furfural hasil hidrolisis dengan pretreatment pemanasan resistive di semua variasi perlakuan menunjukan nilai yang kurang lebih sama dengan nilai $\mathrm{Rf}$ dari furfural standar. Hal ini mengindikasikan senyawa yang dihasilkan dari hidrolisis alang-alang adalah furfural. Dari hasil di atas, maka dapat dikatakan bahwa perlakuan pretreatment pemanasan resistive tidak mengurangi kualitas dari furfural yang dihasilkan, melainkan dapat meningkatkan kuantitas dari furfural yang didapat bila dibandingkan dengan perlakuan yang tanpa pretreatment pemanasan resistive.

Furfural dengan rendemen terbaik, yakni hasil isolasi melalui tahap pretreatment pemanasan resistive dengan perlakuan suhu $65^{\circ} \mathrm{C}$ serta konsentrasi $\mathrm{NaOH} 0,01 \mathrm{M}$ diuji secara kualitatif dengan pengamatan pada parameter warna, bentuk, bau serta pengukuran densitas dan dibandingkan dengan furfural standar dan furfural teoritis. Hasil pengamatan dapat dilihat pada Tabel 4:

Tabel 4. Parameter kualitatif furfural

\begin{tabular}{llll}
\hline Parameter & $\begin{array}{c}\text { Furfural } \\
\text { Hasil } \\
\text { Isolasi** }\end{array}$ & $\begin{array}{c}\text { Furfural } \\
\text { Standar }\end{array}$ & $\begin{array}{c}\text { Furfural } \\
\text { Teoritis* }\end{array}$ \\
\hline Warna & $\begin{array}{l}\text { Kuning } \\
\text { muda } \\
\text { agak } \\
\text { kecoklatan }\end{array}$ & $\begin{array}{l}\text { Coklat } \\
\text { kehitaman }\end{array}$ & $\begin{array}{l}\text { Kuning } \\
\text { muda agak } \\
\text { kecoklatan }\end{array}$ \\
& Cairan & Cairan pekat & Cairan pekat \\
\hline Bentuk & pekat & & \\
\hline Bau & Manis & Manis & Almond \\
\hline Densitas & $1,14 \mathrm{~g} / \mathrm{ml}$ & $1,15 \mathrm{~g} / \mathrm{ml}$ & $1,16 \mathrm{~g} / \mathrm{ml}$
\end{tabular}

*) secara teoritis dikutip dari NIST

**) furfural pretreatment $(0,01-65)$

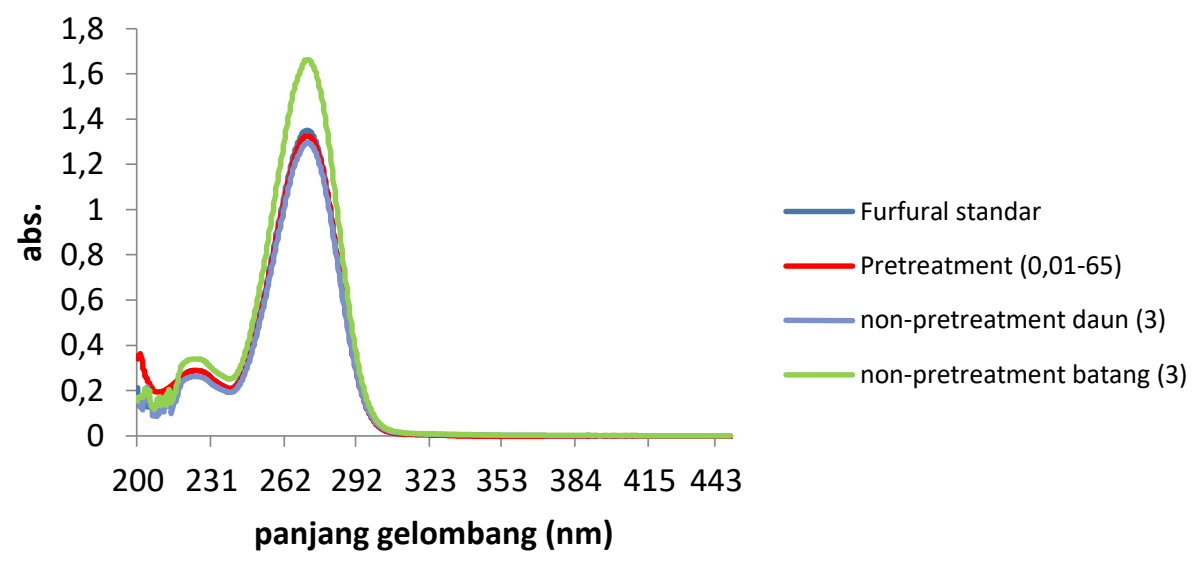

Gambar 3. Hasil spektrum UV-Vis furfural

Tabel 5. Data pengamatan spektra furfural

\begin{tabular}{lccccc}
\hline \multicolumn{1}{c}{ Vibrasi $\left(\mathbf{c m}^{-1}\right)$} & \multicolumn{4}{c}{ Furfural } \\
\cline { 2 - 6 } & Teoritis* & Standar & $\begin{array}{c}\text { Non-pretreatment } \\
\text { daun }\end{array}$ & $\begin{array}{c}\text { Non-pretreatment } \\
\text { batang }\end{array}$ & Pretreatment \\
\hline Stretching C-H aromatis & $3150-3050$ & 3134,11 & 3132,18 & 3132,18 & 3133,15 \\
Stretching C-H aldehid & $2900-2800$ & 2848,67 & 2848,67 & 2850,59 & 2849,63 \\
Stretching C=O aldehid & $1740-1620$ & 1674,10 & 1668,31 & 1674,10 & 1674,10 \\
Stretching C=C aromatis & $1600-1475$ & 1568,02 & 1568,02 & 1568,02 & 1568,02 \\
Bending C-H aldehid & $1500-1300$ & 1392,51 & 1392,51 & 1392,31 & 1393,47 \\
Stretching C-O-C & $1300-1000$ & 1155,28 & 1155,28 & 1155,28 & 1157,21 \\
\hline
\end{tabular}

*) Berdasarkan Fessenden dan Fessenden (1982) dalam Ardiana dan Mitarlis (2012)

Dari analisis furfural hasil hidrolisis dengan spektrofotometer UV-Vis didapatkan bahwa $\lambda_{\max }$ dari dari semua furfural hasil hidrolisis memiliki nilai hampir sama dengan furfural standar, yaitu
271,00 dan tidak jauh berbeda dengan $\lambda_{\max }$ furfural teoritis, yaitu $276 \mathrm{~nm}$. Sehingga dapat disimpulkan bahwa furfural hasil hidrolisis memiliki kemurnian yang tinggi. 


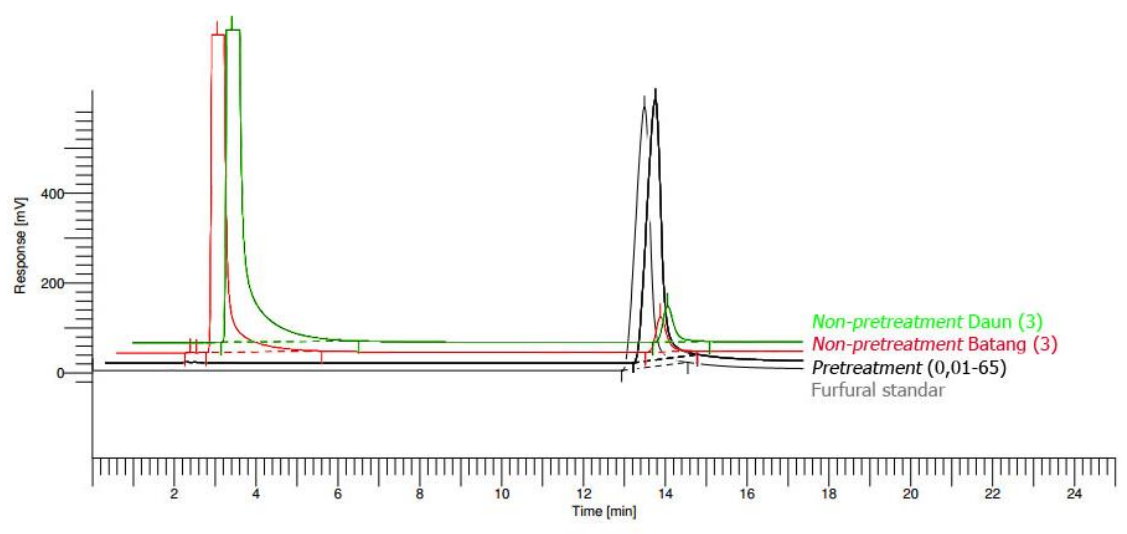

Gambar 4. Spektrum hasil analisis GC dari furfural

Dari data pada Gambar 3 dan Tabel 5 menunjukkan bahwa furfural hasil hidrolisis alang-alang di semua perlakuan memiliki daerah serapan yang hampir sama dengan serapan furfural standar dan furfural teoritis, yaitu daerah serapan 3132,18-3133,15 $\mathrm{cm}^{-1}$ untuk stretching $\mathrm{CH}$ aromatis, daerah serapan 2848,67-2850,59 $\mathrm{cm}^{-1}$ untuk stretching $\mathrm{C}-\mathrm{H}$ aldehid, daerah serapan 1681,06-1681,68 $\mathrm{cm}^{-1}$ untuk stretching $\mathrm{C}=\mathrm{O}$, daerah serapan $1568,02 \mathrm{~cm}^{-1}$ untuk stretching $\mathrm{C}=\mathrm{C}$ aromatis, daerah serapan $1155,28-1157,21 \mathrm{~cm}^{-1}$ untuk stretching C-OC,dan daerah serapan 1392,31-1393,47 cm cm $^{-1}$ untuk bending $\mathrm{C}-\mathrm{H}$ aldehid. Dari uraian di atas, furfural hasil sintesis alang-alang tersebut memiliki gugus-gugus penyusun furfural meskipun masih terdapat gugus-gugus penyusun lainnya. Sehingga bisa dikatakan bahwa senyawa yang dihasilkan dari proses hidrolisis alang-alang adalah memang senyawa furfural.Analisis kadar kemurnian furfural hasil isolasi dilakukan menggunakan Gas Chromatography (GC) HP 5890 dalam pelarut etanol. Hasil GC di semua sampel menunjukan waktu retensi yang hampir sama dengan furfural standar, yakni beriksar pada 13,54-13.67 menit. Dari hasil analisis furfural hasil hidrolisis melalui pretreatment (sampel 0,01-65) terdapat satu puncak pada spektrum yang merupakan senyawa furfural dengan kemurnian $100 \%$. Kemudian dari hasil analisis furfural hasil hidrolisis tanpa pretreatment didapatkan dua puncak pada spektrum, baik pada furfural hasil hidrolisis daun (sampel 3) maupun pada furfural hasil hidrolisis batang (sampel 3). Puncak pertama menunjukkan adanya etanol yang merupakan pelarut, sedangkan puncak kedua menunjukkan adanya senyawa furfural. Pada spektrum furfural hasil hidrolisis daun diperoleh kadar sebesar 92,50\%, sedangkan pada spektrum furfural hasil hidrolisis batang diperoleh kadar sebesar $91,75 \%$.

\section{KESIMPULAN}

Penurunan konsentrasi larutan $\mathrm{NaOH}$ dan suhu pretreatment cendrung dapat menghasilkan rendemen lebih banyak, dengan rendemen terbanyak yaitu sebesar 7,34\% dengan perlakuan konsentrasi larutan $\mathrm{NaOH}$ $0,01 \mathrm{M}$ dan suhu pretreatment $65^{\circ} \mathrm{C}$. Karakteristik furfural hasil sintesis alang-alang memiliki hasil spektra UV-Vis memiliki nilai $\lambda$ maks berkisar antara 271,00-271,50 nm, hasil spektra FT-IR mengandung gugus fungsi furfural yakni $\mathrm{C}-\mathrm{H}$ aromatis, $\mathrm{C}-\mathrm{H}$ aldehid, $\mathrm{C}=\mathrm{O}$ aldehid, $\mathrm{C}=\mathrm{C}$ aromatis, bending $\mathrm{C}-\mathrm{H}$ aldehid, dan $\mathrm{C}-\mathrm{O}-\mathrm{C}$, dan hasil analisa GC menunjukan furfural hasil hidrolisis memiliki kemurnian diatas $91,75 \%$.

\section{DAFTAR PUSTAKA}

Wijanarko, A., Witono, J. A., dan Wiguna, M. S. 2006. Tinjauan Komprehensif Perancangan Awal Pabrik Furfural Berbasis Ampas Tebu di Indonesia. Indonesian Oil and Gas Community. Komunitas Migas Indonesia

Kartikasari, S.D., Nurhatika S., dan Muhibuddin, A. 2013. Potensi Alang-alang (Imperata cylindrica (L.) Beauv) dalam Produksi Etanol Menggunakan Bakteri Zymomonas mobilis. Sains Dan Seni Pomits 2(2): 23373520

Sun Y, Cheng J. 2002. Hydrolysis of Lignocellulosic Materials For Ethanol Production: A Review. Bioresource Technol. 83:1 - 11

Gauru, I. 2002. Produksi Furfural Dari Kulit Kacang Tanah Ditinjau Dari H2SO4 Dan 
Substrat, Berbagai Konsentrasi H2SO4

Serta Lama Waktu Pemanasan. Jurusan

Kimia Fakultas Sains Dan Matematika, Universitas Kristen Satya Wacana, Salatiga.

Setyadji, M. 2007. Hidrolisis Pentosan Menjadi Furfural Dengan Katalisator Asam Sulfat Untuk Meningkatkan Kualitas Bahan Bakar Mesin Diesel. Prosiding PPI - PDIPTN, Batan. Yogyakarta.

Elwin, Lutfi, M., dan Hendrawan, Y. 2014. Analisis Pengaruh Waktu Pretreatment dan Konsentrasi $\mathrm{NaOH}$ terhadap Kandungan Selulosa, Lignin dan Hemiselulosa Eceng Gondok Pada Proses Pretreatment Pembuatan Bioetanol. Jurnal Keteknikan Pertanian Tropis dan Biosistem 2(2): 110116

Dehani, F. R. P., Argo, Bambang Dwi, dan
Yulianingsih, R. Pemanfaatan Iradiasi Gelombang Mikro untuk Memaksimalkan untuk Proses Pretreatment Degradasi Lignin Jerami Padi (Pada Produksi Bioetanol). Jurnal Bioproses Komoditas Tropis 1(1).

Jalaluddin dan Rizal, S. 2005. Pembuatan pulp dari jerami padi menggunakan natrium hidroksida. Jurnal Sistem Teknik Industri. 6 (5): 53-56.

Normalasari, L., Kumalasari, D., Prakoso, C. A. H., Kusumaningtyas, M., dan Ramadhan, M. T. 2015. Pretreatment Degradasi Lignin Jerami Padi Berbasis Resistive Heating pada Pembuatan Bioetanol. Artikel Penelitian PIMNAS. Universitas Brawijaya. Malang. 